\title{
Integrated Analysis of Retail Trade Areas: (2) Empirical Validation
}

\author{
H du Toit \\ C E Cloete \\ Department of Construction Economics \\ University of Pretoria, South Africa
}

\section{Keywords}

Market analysis, retail trade areas, central place theory, market saturation, retail demand potential.

\begin{abstract}
An integrated analysis of retail trade areas was proposed in Part I of two papers on the analysis of trade areas. The proposed analysis incorporated four techniques, namely the Multi-Criteria Saturation Index (MCSI), Retail Diversification Index (RDI), Demand Density Analysis (DDA) and Growth Matrix (GM). Improvements to the analogue method are also proposed, including economic indicators to account for the time value of money.

In Part II the validity of the proposed integrated analysis is tested, based on a comparison of actual versus forecast shopping centre sales data for twelve shopping centres in South Africa. A negligible difference was observed between actual and forecast sales.
\end{abstract}

Corresponding author: C E Cloete

Email addresses for corresponding author: chris.cloete@up.ac.za

First submission received: $13^{\text {th }}$ March 2018

Revised submission received: $15^{\text {th }}$ May 2018

Accepted: $18^{\text {th }}$ June 2018

\section{Introduction}

Part I of this two-part paper proposed an integrated approach for the analysis of retail trade areas. The techniques that form part of the integrated approach include the Multi-Criteria Saturation Index (MCSI), the Retail Diversification Index (RDI), Demand Density Analysis (DDA) and Growth Matrix (GM). It was argued that the application of a combination of the proposed techniques enhances market insight and articulates attributes of the retail environment that are not reflected through the application of traditional trade area analysis approaches. It was concluded that the proposed techniques therefore could improve decisions about the feasibility of proposed shopping centres.

Although holding the promise of improving decision-making in shopping centre development, the validity of the proposed integrated approach needs to be verified empirically. This is done in the present paper.

\section{Methodology}

The proposed approach was applied to twelve (12) new shopping centres in South Africa developed between 2007 and 2016. To test the validity of the proposed methodology, the initial sales forecasts for a selection of centres are compared to actual centre sales performance.

The centres were selected on the following basis:

An initial market assessment and sales forecast must have been performed for the development; Sufficient time must have lapsed to allow for the development to become operational and for sales to mature;

The larger part of the sample should ideally comprise contested developments, i.e. an independent report compiled by an expert in which the demand and sales forecasts made by this author, were criticized by another independent analyst on account of methodology; 
A limited number of unopposed developments for which the same approach was followed are incorporated for purposes of comparison and to broaden the sample.

The sample of centres available for analysis was influenced by the willingness of shopping centre owners to disclose confidential information. Actual sales figures utilised in the test for validity were disclosed by owners on condition that centre names are not publicised. The sample subjects (Figure $1 \&$ Table 1) analysed in the test for validity include:

- four 4 convenience centres (measuring $<12000 \mathrm{~m}^{2}$ );

- a big box retail outlet (measuring between $2000 \mathrm{~m}^{2}$ and $15000 \mathrm{~m}^{2}$ );

- a value centre (measuring between $10000 \mathrm{~m}^{2}$ and $50000 \mathrm{~m}^{2}$ );

- a community centre (measuring between $12000 \mathrm{~m}^{2}$ and $25000 \mathrm{~m}^{2}$ );

- a small regional centre (measuring between $25000 \mathrm{~m}^{2}$ and $50000 \mathrm{~m}^{2}$ ); and

- four regional centres (measuring between $50000 \mathrm{~m}^{2}$ and $100000 \mathrm{~m}^{2}$ ).

The centres are geographically distributed between five provinces in South Africa, namely Gauteng, Kwazulu-Natal, Limpopo, North West and Mpumalanga.

The emphasis of the assessment is on calculating the percentage variance between actual sales and forecast sales for a particular year - not on actual monetary sales values for all centres in the same year. A direct timeline comparison is not required and accounting for the time value of money in this context is therefore not a prerequisite in as far as the test for validity is concerned. Market idiosyncrasies, including total market income, disposable income levels and associated purchase power variances are accounted for in the method. Performance figures are therefore comparable without further time value of purchase power parity adjustments required.

\section{Results}

Shopping centre data for the respective centres in the sample are summarised in Figure 1.

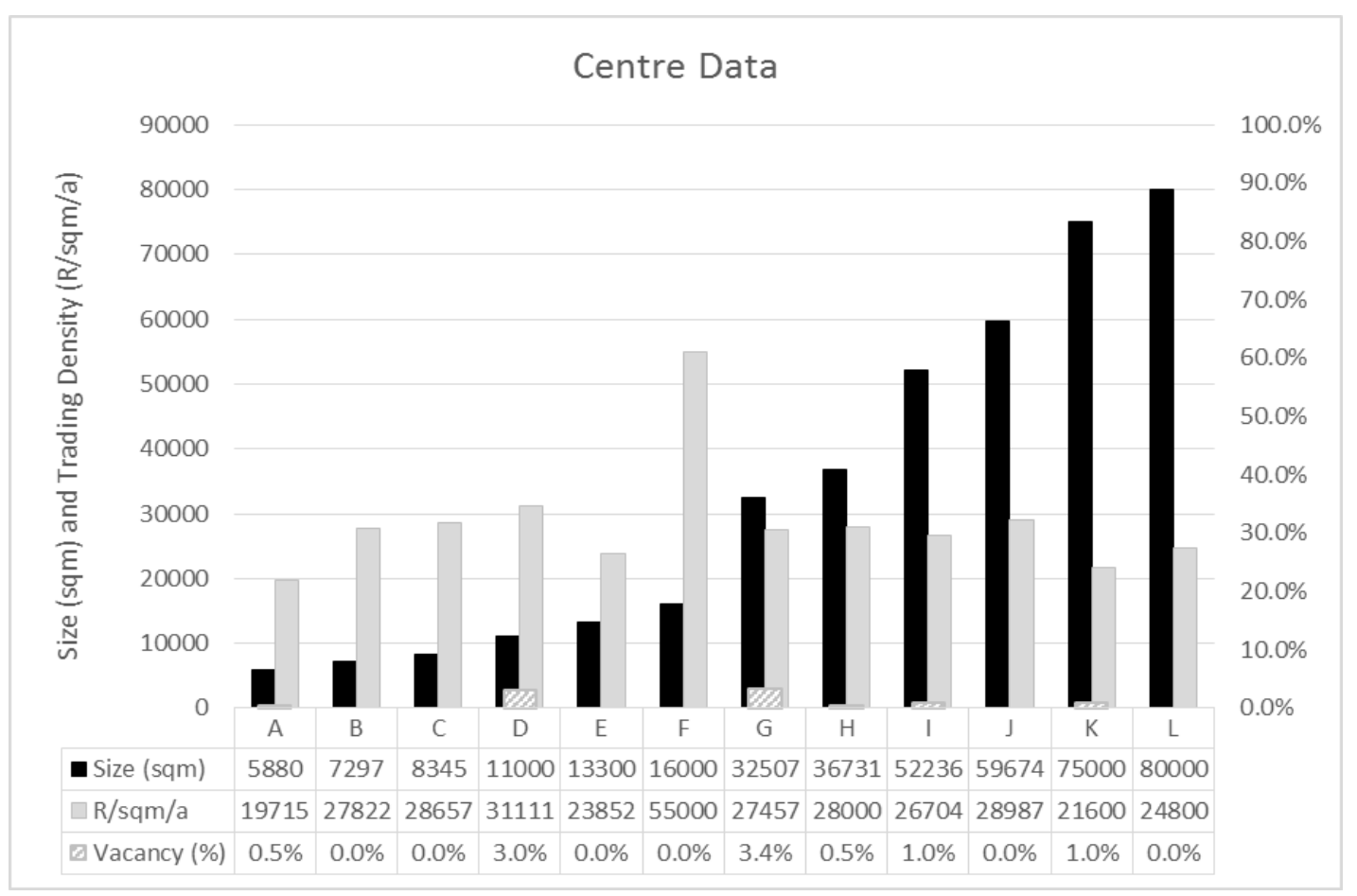

Figure 1: $\quad$ Summarised centre data for the Sample of Twelve Centres Source: Flanagan 2017, Beyers 2017, Kriek 2017, Pickard 2017, Baladakis E Baladakis 2017 


\begin{tabular}{|l|l|l|l|}
\hline Centre & Size (sqm) & Vacancy $(\%)$ & 19715 \\
\hline A & 5880 & $0.5 \%$ & 27822 \\
\hline B & 7297 & $0.0 \%$ & 28657 \\
\hline C & 8345 & $0.0 \%$ & 31111 \\
\hline D & 11000 & $3.0 \%$ & 23852 \\
\hline E & 13300 & $0.0 \%$ & 55000 \\
\hline F & 16000 & $0.0 \%$ & 27457 \\
\hline G & 32507 & $3.4 \%$ & 28000 \\
\hline H & 36731 & $0.5 \%$ & 26704 \\
\hline I & 52236 & $1.0 \%$ & 28987 \\
\hline J & 59674 & $0.0 \%$ & 21600 \\
\hline K & 75000 & $1.0 \%$ & 24800 \\
\hline L & 80000 & $0.0 \%$ & \\
\hline
\end{tabular}

Table 1:Summarised centre data for the Sample of Twelve Centres

Source: Flanagan 2017, Beyers 2017, Kriek 2017, Pickard 2017 and Baladakis and Baladakis 2017

A comparison of centre vacancy rates against the industry benchmark per centre type is provided in Figure 2 and Table 2. Results of the test for validity are summarised in Figure 3 and Table 3.

In five instances (Centres A, B, C, E \& F) vacancies were zero and in four other instances vacancies were reported to be $1 \%$ or less (Centres $\mathrm{H}, \mathrm{I}, \mathrm{J} \& \mathrm{~L}$ ). Low vacancy, although not an absolute indicator of analytical and predictive accuracy, serves as proxy for centre performance. Centre performance is also influenced by factors such as design, tenanting, management and market research accuracy. The sample centres were all developed by reputable companies and aspects such as design, tenanting and management were considered to be of similar quality. The term reputable in the context of this paper denotes a combination of experience, workmanship and ethics: these companies are privately owned, have been operational for decades and none are implicated in the South African State Capture debacle, which primarily involves service providers to State owned utilities companies, including Eskom (the national electricity provider).

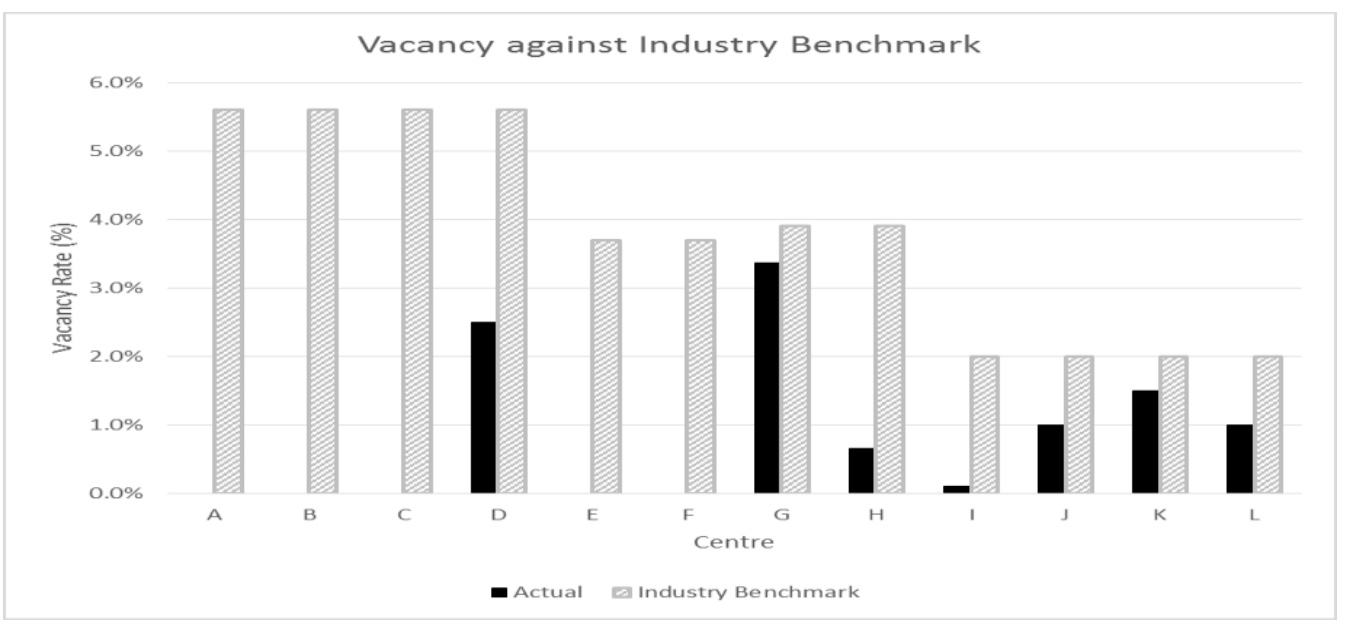

Figure 2:Vacancy rate comparison for the Sample of Twelve Centres Source: Ibid 2017 
The individual and aggregate differences between forecast and actual sales for the sample of twelve centres are summarised in Table 3 and Figure 3.

\begin{tabular}{|c|c|c|c|c|}
\hline Centre & Actual $^{a}$ & $\begin{array}{l}\text { Industry } \\
\text { Benchmarkb }\end{array}$ & Std Dev.P & Std Dev.S \\
\hline A & $0.0 \%$ & $5.6 \%$ & $-100.0 \%$ & 0.03960 \\
\hline B & $0.0 \%$ & $5.6 \%$ & $-100.0 \%$ & 0.03960 \\
\hline C & $0.0 \%$ & $5.6 \%$ & $-100.0 \%$ & 0.03960 \\
\hline $\mathrm{D}$ & $2.5 \%$ & $5.6 \%$ & $-55.4 \%$ & 0.02192 \\
\hline E & $0.0 \%$ & $3.7 \%$ & $-100.0 \%$ & 0.02616 \\
\hline $\mathrm{F}$ & $0.0 \%$ & $3.7 \%$ & $-100.0 \%$ & 0.02616 \\
\hline G & $3.4 \%$ & $3.9 \%$ & $-13.6 \%$ & 0.00375 \\
\hline $\mathrm{H}$ & $0.6 \%$ & $3.9 \%$ & $-83.4 \%$ & 0.02300 \\
\hline I & $0.1 \%$ & $2.0 \%$ & $-95.0 \%$ & 0.01344 \\
\hline J & $1.0 \%$ & $2.0 \%$ & $-50.0 \%$ & 0.00707 \\
\hline K & $1.5 \%$ & $2.0 \%$ & $-25.0 \%$ & 0.00354 \\
\hline L & $1.0 \%$ & $2.0 \%$ & $-50.0 \%$ & 0.00707 \\
\hline
\end{tabular}

Table 2: Vacancy Rate Comparison for the Sample of Twelve Centres

Source: a - Flanagan 2017, Beyers 2017, Kriek 2017, Pickard 2017 and Baladakis and Baladakis 2017

$b$ - SACSC 2016

The market analyses for eight (8) of the twelve centres (A, C, D, F, G, I, J \& K) were the subject of independent scrutiny, critique and cross-examination at hearings and tribunals by specialists who deploy traditional demand modelling techniques. In each instance, the critique was stated that demand had been overestimated and that the development would not be sustainable. The possible effects of externalities on centre performance were identified and isolated. The selected centres are owned by reputable and seasoned developers / investors who employ equally experienced professional teams (architects, engineers, leasing agents, etc.). It was therefore assumed that these aspects are of equal/similar standard in the sample of centres analysed (i.e. these factors are not considered to be key differentiators in the performance of centres analysed). In each instance, the comparison is based on sales figures for the third year of operations to allow for market stabilisation.

The average variance between actual and forecast sales for the sample is $4.4 \%$, with a high of $11.4 \%$ and a low of $0.1 \%$ (Standard Deviation: $5.024 \%$ ). Centre E is situated in a rural/tribal area. The variance in the performance of centre E $(11.4 \%)$ can be attributed to inter alia under-reported census income generally observed in these areas, unrecorded informal sector activity, the influence of remittances (i.e. family members sending money back home from the urban areas), income generated from backyard rental units, coupled with the effects of government subsidies and social grants. If income were to exceed a certain level, the beneficiary would no longer qualify for the subsidy. In this manner, subsidy dependence would appear to have inadvertently been incentivised. According to the 2011 Census (Stats SA 2013) $77.7 \%$ of the population in Limpopo Province reside in tribal areas and the unemployment rate in tribal areas is $51.1 \%$, compared with $23.8 \%$ in urban areas. Retail sales data for shopping centres in tribal and township areas continue to exceed the norm and highlights the problems associated with understated Census-based income data in these areas. Significantly more pronounced differences have been observed in other tribal and township areas, including Mamelodi (Demacon 2016 \& Fernridge 2016), 
Soweto (Demacon 2009, 2010a, 2010b \& 2015a) and Katlehong, Tokoza and Vosloorus (Demacon 2015b \& 2017).

\begin{tabular}{|l|l|l|l|l|}
\hline Centre & Actual & Forecast & \multicolumn{2}{l}{ Difference } \\
\hline A & 19715 & 20298 & $-2.9 \%$ & 2004 \\
\hline B & 27822 & 26000 & $7.0 \%$ & 2012 \\
\hline C & 28657 & 28317 & $1.2 \%$ & 2011 \\
\hline D & 31111 & 30129 & $3.3 \%$ & 2015 \\
\hline E & 23852 & 21419 & $11.4 \%$ & 2012 \\
\hline F & 59500 & 56453 & $5.4 \%$ & 2013 \\
\hline G & 27457 & 25500 & $7.7 \%$ & 2012 \\
\hline H & 27500 & 28000 & $-1.8 \%$ & 2017 \\
\hline I & 26037 & 25131 & $3.6 \%$ & 2015 \\
\hline J & 28987 & 30460 & $-4.8 \%$ & 2017 \\
\hline K & 21600 & 22329 & $-3.3 \%$ & 2013 \\
\hline L & 24800 & 24830 & $-0.1 \%$ & 2017 \\
\hline Average & & & $4.4 \% *$ & \\
\hline Std Deviation & & & $5.024 \%$ & \\
\hline Actua oersus For & & & \\
\hline
\end{tabular}

Table 3: Actual versus Forecast Sales (Trading Density) Comparison for the Sample of Twelve Centres $\left(\mathrm{R} / \mathrm{m}^{2} / \mathrm{a}\right)$

Source: Calculations based on Flanagan 2017, Beyers 2017, Kriek 2017, Pickard 2017 and Baladakis 2017

*Note: Adjusted for negativity

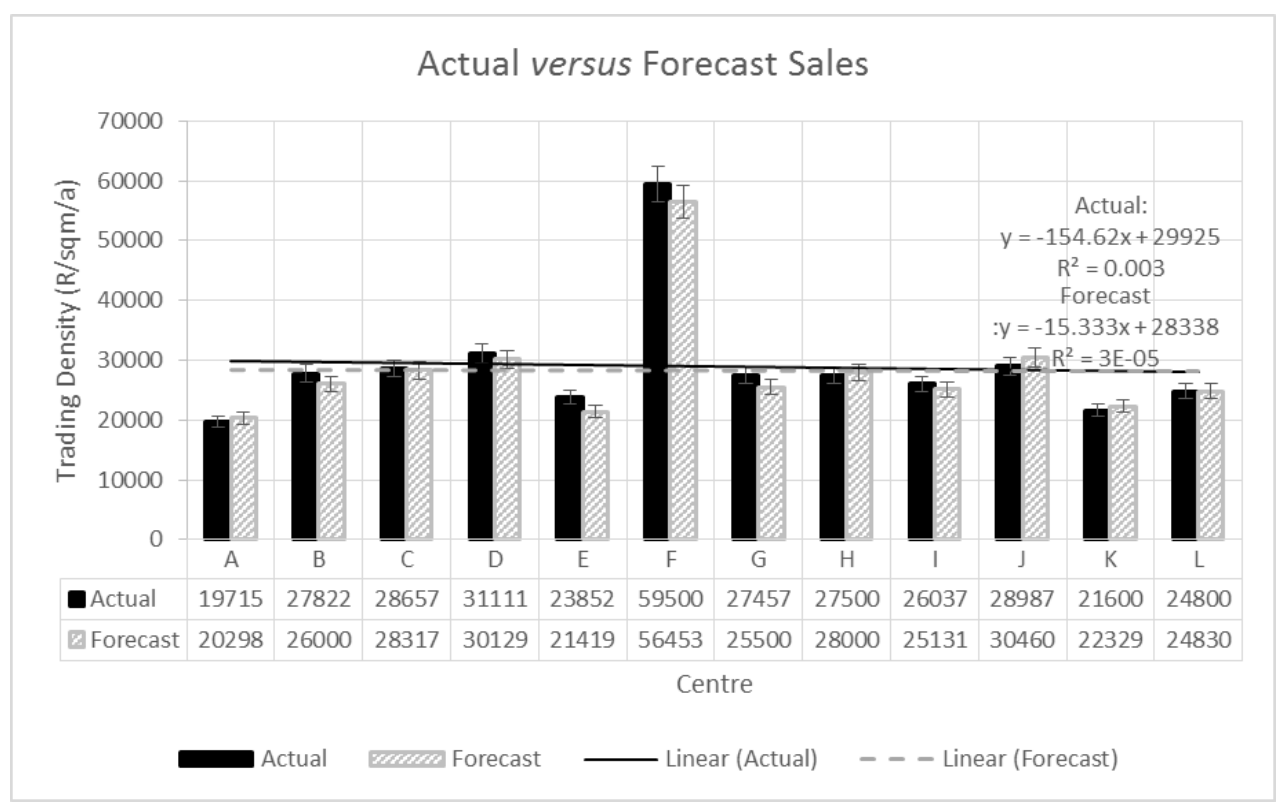

Figure 3:Actual versus Forecast Sales (R/m²/a) Comparison for the Sample of Nine Centres 
The $\mathrm{R}^{2}$ values (Figure 3) are not a meaningful indicator of accuracy due to the inherent data distribution. Centre F, for instance, is a big box trader with high trading density attributes compared with similar sized conventional shopping centres. The negligible observable delta between the actual and forecast trend line is an indication of predictive accuracy: a variance of $4.4 \%$ between forecast and actual sales was calculated for the sample of twelve centres.

In five (5) instances, forecast sales were higher than actual sales achieved by an average of $2.6 \%$. In the remaining seven (7) instances, actual sales exceeded forecast sales by an average of $5.6 \%$.

The small variance between forecast and actual sales performance observed is indicative of descriptive and predictive analytical accuracy - descriptive in terms of prevalent market conditions and predictive in regards to future sales and/or demand estimations.

\section{Conclusions}

An improved methodology for retail trade area analysis had been proposed in an earlier paper, based upon the multi-criteria saturation index (MCSI), the retail diversification index (RDI), demand density analysis (DDA), growth matrix (GM) and refinements to the analogue model. The validity of the proposed methodology was tested in the present paper by comparing actual versus forecast centre sales.

It was found that the proposed techniques accurately model dimensions of demand that traditional techniques are incapable of modelling. Based on the negligible margin of difference between actual and forecast sales for the sample of centres, it is concluded that the proposed integrated approach is empirically sound, affords a high degree of statistical accuracy and adds substantive insight to retail trade area analysis and demand modelling. A combination of the above techniques enhances area selection and asset holding decisions.

The accuracy of sales forecasts made by application of the four techniques should improve the quality of investment decision making. The integrated approach that incorporates the proposed techniques has similarly led to investors being advised not to pursue certain investment opportunities. Retailers (i.e. tenants) also stand to benefit from new insights offered.

\section{Research limitations and direction for further research}

Although the MCSI was developed to be responsive to socio-economic differences between markets, the effects of politics on business and consumer confidence was not directly factored. Aspects such as real estate ownership (i.e. property rights), or the absence thereof in rural/tribal areas of South Africa, may influence real estate investment, regardless of latent demand potential.

Research could be expanded to cover a broader spectrum of countries. Longer term time series data collated over time could add further value to the techniques developed.

The research findings presented articulate emerging socio-economic dynamics in an exceedingly complex South African landscape. Opportunities for further research include:

- the impact of the dualistic SA land tenure system on economic growth and real estate development;

- the economic, fiscal and real estate impacts of understated income in Second Economy (township and rural/tribal) markets of SA;

- diverging socio-economic profiles and perspectives on SA society (including income inequality) created by respectively census based income data versus livings standard measurement instruments (e.g. LSM) and the implications for the Gini Coefficient, planning, policy, taxation and real estate development;

- a rethink of the traditional SA Retail Hierarchy - scope exists for a lateral solution, incorporating aspects of agglomeration, multiple trade areas and trade area overlap;

- research the impacts and implications of new real estate funds created by the Public Investment Corporation (PIC) in SA, including the potential impacts that transformation of the tribal system could have on land ownership, real estate investment and economic development.

\section{References}

Baladakis A. \& J. Baladakis. (2017). Personal Communication with Messrs Alex and John Baladakis, Owners of various Johannesburg Pickn Pay franchise stores. Johannesburg, 18 July 2017. 
Beyers P. (2017). Personal Communication with Mr Pieter Beyers, Senior Development Manager, Moolman Group. Pretoria, 13 June 2017.

Demacon Market Studies. (2009). Chris Hani Crossing Market Research E Recommendations. Unpublished.

Demacon Market Studies. (2010a). Jabulani Mall Market Analysis. Unpublished.

Demacon Market Studies. (2010b). The Impact of Shopping Centres on Township Economies. Unpublished.

Demacon Market Studies. (2015a). Protea Glen Mall Market Research E Recommendations. Unpublished.

Demacon Market Studies. (2015b). Tokoza Mall Market Research E Recommendations. Unpublished.

Demacon Market Studies. (2016). Mams Mall Market Analysis. Unpublished.

Demacon Market Studies. (2017). Tokoza Kwesine PRASA Station Retail Potential Analysis E Recommendations. Unpublished.

Fernridge. (2016). Mamelodi Consumer Profile and Income Comparison. Unpublished.

Flanagan P.( 2017). Personal Communication with Mr Patrick Flanagan, Director, Flanagan E Gerard. 6 June 2017.

Kriek J. (2017). Personal Communication with Mr Johann Kriek, Director, Resilient Property Income Fund. Pretoria, 18 July 2017.

Pickard H. (2017). Personal Communication with Mr Hannes Pickard, Managing Director, Dorpstraat (formerly Retail Africa). Pretoria, 19 July 2017.

SACSC (2016). Shopping Centre Directory 2015/2016. South African Council of Shopping Centres: Sandton. 